form $A \wedge A D E$ ENISK

Mathilde Frances Lind PhD Candidate

Vol I4, No 2 (2O2I)

\title{
Spinning wool on Kihnu Island
}

The ecology of heritage sheep and textile crafts

\begin{abstract}
Wool crafts are an essential part of cultural heritage and daily life on Kihnu Island in Estonia, and they begin with animal husbandry and wool preparation. People and sheep cooperatively produce wool, maintain the land through conservation grazing, and facilitate heritage activities while external and internal conditions and forces, like changing economic and demographic factors, provide challenges and friction. An ecological study of wool crafts in context requires attention to creative processes, tools, materials, landscapes, and human and other-than-human animals that are engaged in complex flows of activity and meaning with one another. Both ethnographic encounters and autoethnographic reflections on craft practice provide vital insight into these entanglements.
\end{abstract}

Keywords:

wool crafts, ecology of materials, practice-led research, cultural heritage, animal-human relations

\section{INTRODUCTION}

A small Estonian island in the Gulf of Riga, Kihnu is known for its distinctive handicrafts, traditional music and dance, and cultural landscapes, but many of the most visually iconic parts of Kihnu culture are made with wool. Specifically, the handwoven striped skirts of Kihnu are the most identifiable aspect of local material culture, featuring braided red trim and stunning colors ranging from bright reds and pinks to the more somber shades of blue worn in years of mourning, although hand-knitted mittens, jumpers, hats, socks, and stockings with intricate, high-contrast patterns are also celebrated. While knitters on the island no longer produce most of their yarn by hand, local methods of wool processing and spinning are still known on the island and form a living tradition, in contrast to the overall lack of continuity in traditional spinning knowledge in most of Estonia. 
About a week before the first rush of summer tourists arrived, I came to the Kihnu Museum to meet with Kalju Elvi, one of the master craftswomen of the island, who had agreed to initiate me into the mysteries of carding and handspinning yarn in the traditional Kihnu style. Elvi showed me how to card and spin using hand cards and a spinning wheel, old tools of the standard Estonian types. Although I had difficulty with the Kihnu dialect, we compensated through gestures and a shared understanding of the qualities of wool, basic methods of manipulating it, and the working characteristics of the tools. By the end, I had the technique "in my hand", as Estonians say, and I was able to practice later at home until it became second nature. As I did, I referred to my photographs and videos of Elvi's techniques and to footage from the Kihnu Museum's archives that showed the same technique being used in the 1930s, and I was able to test whether the spinning style could be done with different types of wool and different wool preparation methods and tools. In this way, fieldwork documentation and hands-on experience supplemented each other and helped me to understand the technique and how it complements the specific qualities of the tools and materials.

As a practitioner and teacher of handspinning as well as a researcher, I understand crafts as relational processes between people, tools, and materials. The joy of making comes with finding methods that utilize appropriate tools to bring out and intensify desirable qualities of the materials and satisfy the imagination of the maker. In experiencing this living craft tradition on Kihnu Island, I found that the materials, tools, and knitting and weaving styles complement each other, helping practitioners to realize the aesthetic possibilities of local wool. Along with native sheep and traditional husbandry, these beings, materials, skills, landscapes, and forms negotiate a dense network of shifting mutuality, even while external and internal conditions and forces, like changing economic and demographic factors, provide challenges and friction.

Globally, wool is a widespread and fundamental material that can serve as a lens for understanding cultural values and traditions; however, it is important to attend to the materiality of wool and its tangible presence in the world. Deep investigation of materials helps the researcher to "embed art in life's thickness" (Glassie, 2007, p. xiv) and reveal an expanded view of creative processes as practical and reciprocal activities of everyday life. In recent decades, craft researchers have applied ideas about relational ontology - which have predecessors in worldviews from outside the ambit of the Western philosophical traditions through which they are often traced (Bird-David, 1999, p. S77; Vosters, 2014, p. 111; Wisnoski, 2019, p. 216) - to making, recasting materials and tools as active partners in creative processes, rather than passive objects manipulated by active human subjects (Bennett, 2010; Coole \& Frost, 2010; Wisnoski, 2019). This picture is further complicated when the source of the materials consists of other-than-human animals who live in active, complimentary relationships with humans and whose breeding and husbandry manifest the entanglement of human creativity, cultural traditions, landscapes, and the material needs of humans and animals who have for many generations shared, altered, and been altered by an environment with a unique set of physical conditions and constraints (Ryder, 2007, p. viii).

This article represents a set of observations made mid-stream as I continue to engage in longterm ethnographic and practice-led research (as defined in Candy \& Edmonds, 2018) on wool crafts in Estonia, broadly, and on the intersection of animal husbandry patterns and practices with these crafts on Kihnu Island in particular. My aim is twofold. First, I will show how my handwork skills were both helpful in this research and limited in specific ways by my background as a researcher and practitioner. To this end, I will share some snapshots of ethnographic encounters and autoethnographic reflections on the manifestations of craft practice in my research. Second, I will apply Tim Ingold's idea of the "ecology of materials" (2015) to show how a full study of wool in context requires attention to creative processes, tools, materials, landscapes, and human and other-than-human animals that are engaged in complex, entangled flows of activity and meaning with one another. 


\section{TREASURE ISLAND}

Kihnu is a small island in the Gulf of Riga that has historically been both isolated due to its distance from other settlements and connected by wide-ranging seafaring. The nearest inhabited place is Manilaid island $(7.5 \mathrm{~km})$, whose inhabitants have strong cultural, family, and historical ties with Kihnu. Just beyond Munalaid is the port at Munalaid, from which a ferry connects Kihnu with the mainland. The nearest city, Pärnu (41 km from Kihnu), is accessible from this port via car or an hour-long bus ride. During the temperate portion of the year, a ferry runs several times each day; this trip takes just over an hour. However, during the coldest parts of the winter, the gulf may freeze, causing Kihnu to instead be accessible by ice roads (Kuutma, 2002). Although the current population is 690 people (Statistikaamet, 2020), many are not year-round residents.

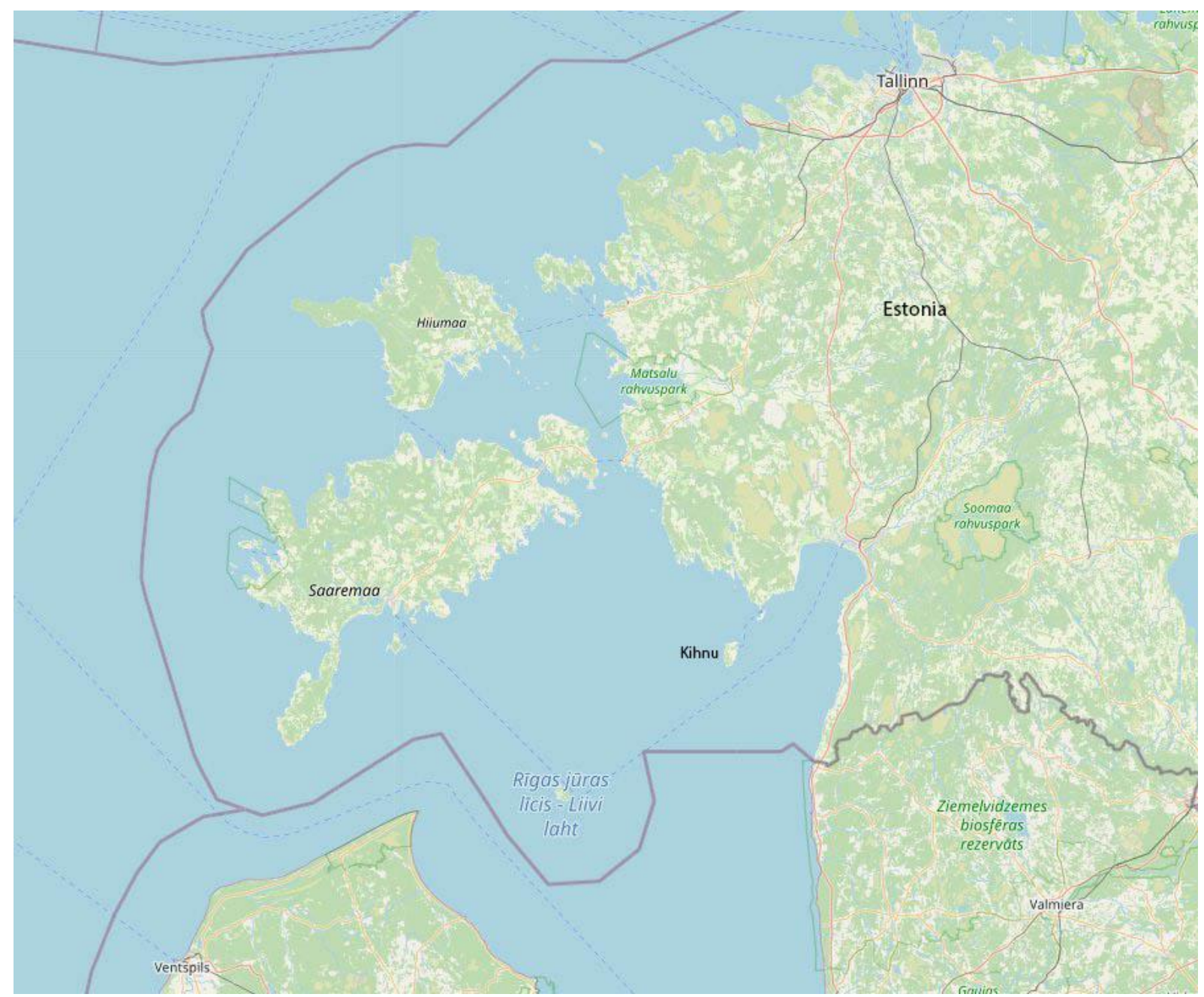

FIGURE 1. Map of Estonia showing the location of Kihnu Island (C) OpenStreetMap contributors (openstreetmap.org)

The island retains a variety of natural and cultural landscapes, including a central ridge of sandy pine forest, coastal meadows, cultivated fields, and homesteads. Meadows are largely maintained by conservation grazing, which is encouraged and funded by the Estonian government, using Estonian native sheep (Eesti maalammas), Scottish highland cattle, and Hereford cattle. These animals graze throughout the warm months and return to their sheds on homesteads in late fall when the weather makes open grazing impractical. The animals may be moved several times throughout the summer to clear and maintain different overgrown meadows by agreement or invitation from the owners of the land. The separation of homesteads and pastureland is also echoed by the placement of communal 
fields; many families maintain separate plots to grow food crops within large, community fields, although some gardens are located adjacent to people's homes.

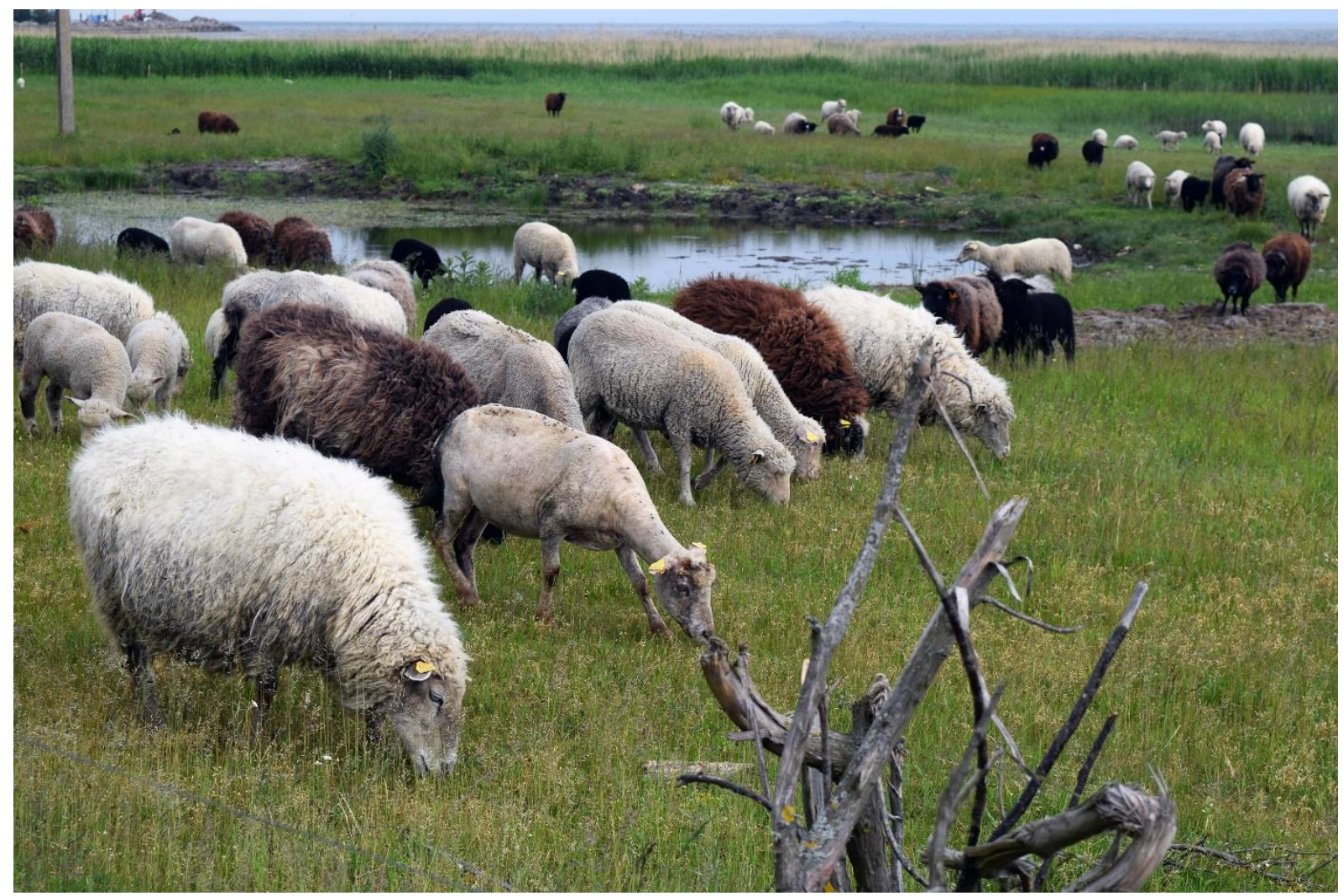

FIGURE 2. Native sheep graze on the coastal meadow near the Kihnu port. They belong to Kolde farm, which is located further inland on the central pine ridge of the island.

Kihnu may be best known for its lively and unique folk culture. In 2002, Kihnu applied for official recognition of its intangible cultural heritage (ICH) through the United Nations. Originally granted this status in 2003, the Kihnu cultural space was officially inscribed in 2008 on the Representative List of the Intangible Cultural Heritage of Humanity (UNESCO, n.d.). Rather than singling out a specific cultural form, the application focused on Kihnu as a "cultural space" with many separate practices that qualify for the funding and attention needed to safeguard them from adverse economic, demographic, and cultural conditions. These include local forms and styles of singing, instrumental music, folk dance, handicrafts, dialect, events, maritime traditions, and agricultural and pastoral practices. Because Manilaid was settled by Kihnu islanders in 1933 (Kuutma, 2002, p. 16) and shares many of these practices, it is included in the Kihnu cultural space.

Among these, women's handicraft "is the visual representation of the island spirit and the islanders' understanding of the world" (Summatavet, 2005, p. 94). Traditional clothing is still worn as daily and festive attire on the island, whose residents are known for safeguarding the quality of their handicrafts and their semiotic significance. The primary materials are wool yarn and cotton print fabrics used for aprons, kerchiefs, and knitting bags (for the significance of cotton print fabrics on Kihnu, see Pukk, 2019). Kihnu women still produce most items by hand for local use and sale to outsiders, which provides a significant source of income. On the mainland, woolen goods from Kihnu are featured in museums and some handicrafts shops, but knockoffs like machine-knitted men's jumpers (troid) or printed cottons that mimic the stripes on Kihnu skirts are common in souvenir shops. Kihnu wool crafts, and the skirts in particular, have come to symbolize a sort of archaic folk culture that is specific to Kihnu 
but that also has been generalized to Estonia as a whole, one that is both commodified and carefully protected.

There are hundreds of different traditional skirts in Estonian folk clothing, but only a few are immediately recognizable to the layperson; the Kihnu skirt is one of them, appearing as a symbolic manifestation of one of Estonia's most vibrant folk cultures. In 1995, Anu Raud, a renowned Estonian weaver and advocate for native craft heritage, was tasked with creating a gift from Estonia to the United Nations. Many Kihnu women donated their handwoven skirts, the most potent manifestation of female identity on the island, and from these Raud created the "Mother Tree" ("Emapuu"). Still displayed at the UN headquarters in New York, it shows the symbolic weight carried by this garment both on the island and for Estonia as a nation (Kuutma, 2002; Reinholm, 2013, p. 87). Because these skirts were woven and worn by Kihnu women, their power is more than merely symbolic - they are potent archives of women's handwork and lives made manifest in wool.

\section{Shepherding and wool processing, then and now}

As of the drafting of Kihnu's UNESCO application in 2002, individual families on the island still kept their own sheep for wool and meat (Kuutma, 2002), but this practice has sharply declined in the intervening years. Most of the sheep on the island now belong to only a few families. With a single family responsible for upwards of 100 sheep, the work of shearing, washing wool, and making yarn has been magnified, and technological solutions must be employed to deal with the scale of the endeavor.

In the past, most of this and other farm work was done by women while the men were at sea. Like other archaic sheep of maritime northern Europe, Estonian native sheep are hardy and small in stature with double-coated wool that is low in lanolin. These traits, combined with the small size of household flocks, meant that it was reasonable for women to shear their own sheep in the spring and fall, although in many parts of Estonia, they would even shear four times per year ("Vill. KL 31," 1941). They caught each sheep and tied its legs together, then removed the wool with handheld shears while sitting on the ground. This wool would be washed, sometimes in the sea, and then carded and spun by hand either at home or in a communal work party accompanied by singing, drinking, and socializing.

Shearing has become a major task that takes the combined efforts of the whole family. One family involved me on shearing day, so I was able to see how they negotiate traditional husbandry and necessary innovation. They raise traditional native sheep and do their own shearing, but they only shear once a year due to the size of the flock. To make the work easier on the shearer's body, they place the sheep on a raised surface. A man does the shearing, taking advantage of his relatively larger frame for the heavy work, which is accomplished using a handheld electric shearing machine. The family members work as a team, holding the sheep's legs to save time instead of tying them together, turning the sheep over as a team, and gathering the wool quickly as it comes off. In this way, we worked as a robust group of seven and managed to shear about 30 sheep in one day, only one fifth of the family's flock.

With so much wool, carting it to the sea for washing makes little sense, so we washed it on site using water from a metal vat heated by the wood-fired oven of the sauna. After drying in the sun for several days, the wool is packed away until a work party can be gathered to pick the wool by hand, fluffing it up lock by lock before sending it to the mill. There are no mills on the island, so the shepherd brings her clean, picked wool to a mill on the mainland to have it made into yarn, all of which is either used at home or purchased by the island's craftswomen. Much of the yarn used on the island is produced that way, although some people obtain suitable wool from farms on the mainland and have it processed by a mill. One knitter relayed to me the story of how she was given the entire clip of a farm on the mainland for free and had it processed, but she noted that most knitters on the island try to find wool from Kihnu native sheep (Kihnu maalammas), a registered heritage breed, if they have to buy it. One of the largest flocks of such sheep is on the neighboring island of Manija, which is part of the Kihnu cultural space, but carefully conserved flocks can now be found in many regions of Estonia.

Due to the communal nature of Kihnu society, there is a great deal of feedback and interaction between those who raise the sheep and those who obtain yarn from them. The many colors and crisp, sturdy, yet bouncy quality of the wool make it well suited to dense colorwork knitting for garments that are durable, warm, and appropriate for the northern climate and fishing culture. To this end, sheep 
growers are asked to produce clean white and deep black wool, as those are the main colors in the highcontrast patterns on Kihnu mittens and gloves. Many people still know how to spin and card wool by hand but prefer to focus on knitting using the readily available, mostly locally produced wool yarn; however, they can use this latent knowledge to judge the quality of mill-spun yarn. They assess it with a critical eye toward what will produce consistent stitches in stranded colorwork designs, as well as economic considerations: some mills in Estonia spin very consistent yarn with modern equipment, and others spin less consistent yarn with older equipment, but at a lower cost. Inconsistencies are more noticeable in smaller accessories like mittens than in larger garments like jumpers, so the type of projects a knitter specializes in can affect how she prioritizes between yarn quality and cost. Given that crafting in Kihnu is directed toward conservation of traditional forms (Reinholm, 2013, p. 24) - although makers commonly innovate within the community's shared aesthetic standards (Summatavet, 2005, p. 125) - maintaining the quality of knitting seen in previous generations is essential to the continuity of Kihnu wool crafts.

Even though sheep husbandry and yarn production have changed, they have not become activities that are outsourced or hidden from view. Islanders do not obtain their yarn from a shop, and the intermediaries between them and the sheep are usually people with whom they have regular close contact within the community. The animals themselves are a visible and valued part of the coastal landscape. Together, people and sheep produce wool and maintain the land in complex ecological and social entanglements.

\section{Craft practice as a sympoietic technique}

In her book Staying with the Trouble: Making Kin in the Chthulucene, Donna J. Haraway employs the term sympoiesis to describe "making-with," or the idea that all creative and generative activities are enmeshed within "complex, dynamic, responsive, historical systems" (2016, p. 58). Craft practice can be simultaneously isolating and communal, yet it also constitutes an entry point into sympoietic systems of making, aesthetics, and ways of living-in-the-world. Haraway simplifies the idea of sympoiesis to say that we are never alone; I apply it in the context of craft to say that we create in entanglement with others, known and unknown, human and other-than-human, and that all of the "components" in such a system are actants, a term drawn from Bruno Latour and which Jane Bennett defines as "that which has efficacy, can do things, has sufficient coherence to make a difference, produce effects, alter the course of events" (Bennett, 2010, p. viii). That is, each actant has some ability to structure the relationships within the system, sometimes in surprising ways.

My own experience with craft practice in research has been significantly more complicated than I had anticipated, but this may reveal more than if it had been a simple process. I was not brought into a craft tradition as a child, and I did not learn to make anything until I was in my early 20s, when a close friend taught me the basics of knitting in one evening. Thereafter, I was mostly self-taught, but I learned the habit of knitting very loosely, albeit consistently. Coming from the United States, I was exposed to knitting discourse that is encouraging, comforting, and supportive, asserting that knitting is relaxing, therapeutic, communal, and low stakes. Knitters are welcomed to alter patterns, choose different colors, remix, play, innovate, and do things their own way without first mastering traditional forms and techniques. Expertise in knitting traditions just is one of many valid paths according to this view.

In Estonia, I found a strong knitting tradition tied to regional identity, with a much more concrete sense of how things should be. The same kind of free and loose knitting also exists, but that was not the world I had entered into - I had enrolled in classes on Estonian native crafts at the Viljandi Culture Academy, and our work was based on traditions that are deeply integrated with cultural practices and supported by museum artefacts and extensive research. I found that I knitted in a completely different way and needed to learn new methods of holding the needles, keeping tension, and working the stitches. While I could make a perfectly serviceable lace shawl or comfortable cardigan with my old technique, traditional Estonian knitting is generally so tiny and tight that I found it impossible to reproduce it on needles of any size. To do it correctly, my fabric needed to be the right texture, made at the right gauge with approximately the right needles and the right yarn in the right colors, and deviations would have to be explained and justified. While that might sound suffocatingly rigid, I value 
the experience. It gave me tangible examples of well-formed aesthetic systems in geographically and historically situated communities, all of which guided me toward new skills and new ways of thinking about design and materials. Although Estonia is a small country, it has an astonishing diversity of folk clothing, and practice-based experience in the wide range of colors, patterns, textures, structures, and decorative techniques in Estonian knitting has given me abundant resources for my development as a knitter of traditional items and a designer of new ones.

Making is a sympoeitic affair because it happens through complex interactions between makers and materials that are influenced and even directed by makers of the past and present (manifested through their works and words), evaluation by knowledgeable others and a sense of responsibility toward them, community aesthetics, and material conditions. Before I visited Kihnu for the first time, I struggled through knitting a pair of mittens after examples in the Estonian National Museum. It was a painful process at first, for the mittens were very intricate and involved several complicated techniques. When I was halfway through knitting the first one, an Estonian friend showed me a better way to hold the needles and yarn, and suddenly I was able to make much smaller, tighter stitches than before. I had to rip back my colorwork and start over with larger needles, and everything went smoothly after that. As I worked, a pair of mittens from Kihnu were my constant companions, providing me with tactile knowledge about how the fabric should feel and how the finished mittens should fit according to standard practice on the island. I mostly worked on my own, but I was never alone - makers alive and dead offered visible and tactile guidance as I knitted in collaboration with my needles and yarn, whose distinct qualities structured my movements at least as much as my own conscious decisions. To produce the desired results, I could not force them to change for me and suit my established way of making; I had to change to find a way into their flow. I still struggle with the complexity of Kinnu knitting, but focusing on craft practice in advance of fieldwork has given me enough foundational skills to be able to participate in certain creative contexts, establish greater rapport with craftspeople, and better understand what I observe. It is a process not just of knowing through doing but also of making-with and being-with through mindful handwork.

Kihnu can be considered a "closed" culture in that one must have been born and raised on the island to truly be from there, but the islanders also invite outsiders to participate in certain aspects of their culture, as long as forms and techniques are respected and produced faithfully. Knitting is one of these, and the annual Kihnu Knitting Festival brings mainlanders together with local handicraft masters for communal knitting, craft education, and cultural activities. When I sat with other knitters at the most recent festival, my mittens, once inspected and found acceptable, hung in our ad-hoc exhibition. Although they were knitted by an outsider who will never be part of the island community in any real way, the mittens were displayed in material and aesthetic kinship alongside others, telegraphing respect for the creativity, traditions, and skills of the island and its community. 


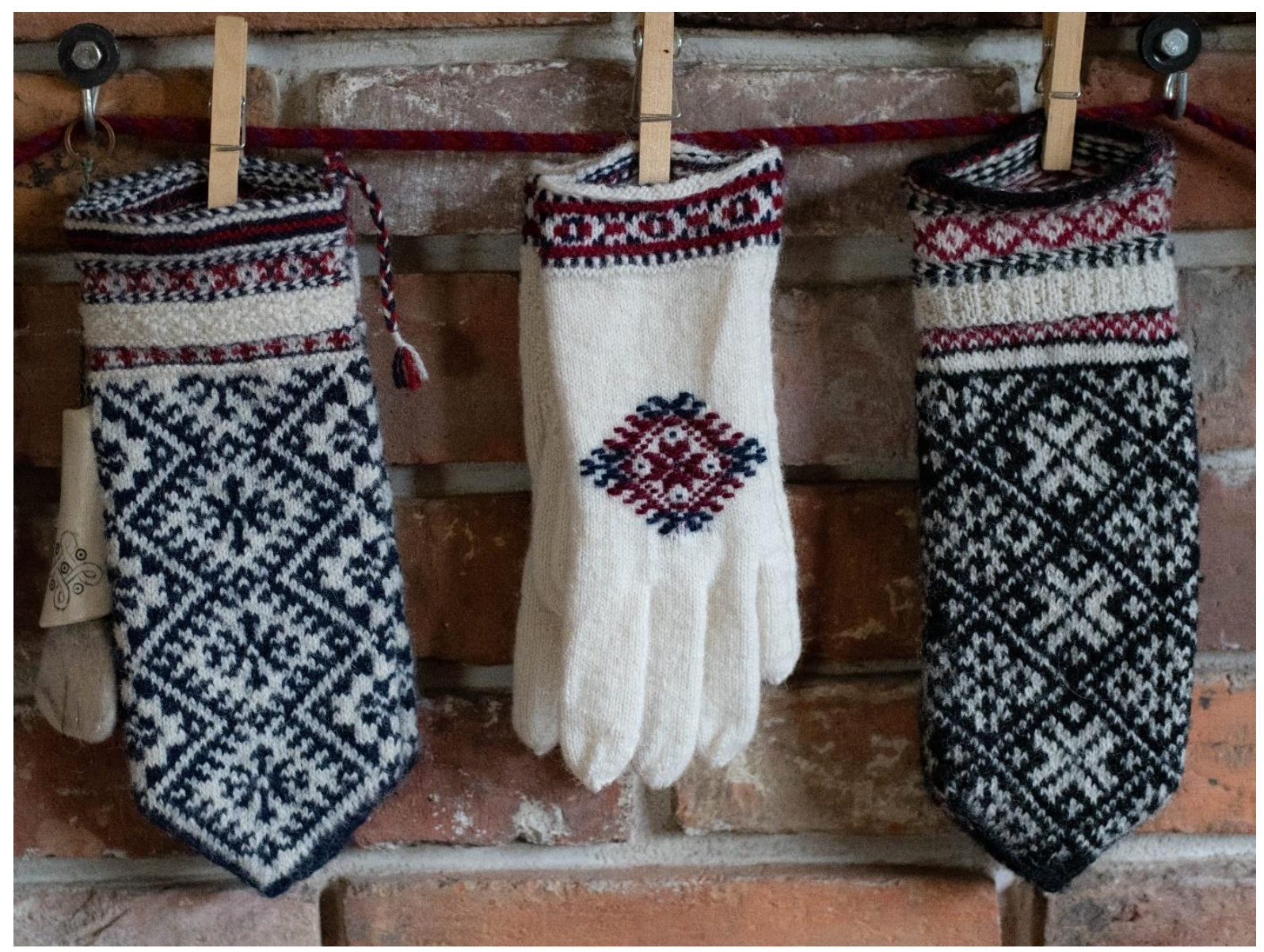

FIGURE 3. The mittens on the left were knitted by the author, the gloves in the middle were knitted by Lohu Ella on Kihnu, and the mittens on the right were purchased from a handicrafts shop in Tallinn in 2019.

\section{Sheep, wool, and the ecology of materials}

In "An ecology of materials", Tim Ingold writes about the process of making as "finding the grain of the way the world is becoming and then turning it this way or that in order to make it match what your own evolving purpose, as a designer or maker, might be" (Ingold, 2015, p. 64). He shows how things are generated ontogenetically, or through a process of growth, not just from the proximate actions that are commonly identified as making. Harvesting and preparing materials, making tools, and constructing molds and jigs are all implicated in the process of making. Instead of an active subject imposing form on materials to create a finished object, the maker "follows the flow of the material and that process of following the material is a correspondence between the flow of the material and the movement and flow of the maker's consciousness" (66). This recalls David Pye's assertion that raw material becomes "good material" via the skilled maker's ability to work (with) it to select the best pieces and develop their qualities; thus, "in speaking of good material we are paying an unconscious tribute to the enormous strength of the traditions of workmanship still shaping the world even now" (Pye, 2015, p. 18).

Wool complicates this picture because it derives from animals who live alongside humans and whose qualities result from the correspondence between their physiological needs, the needs and desires of the humans who breed and maintain them, and the ways that humans and sheep have developed together in geographically and historically situated contexts (Ryder, 2007). Their distinctive needs and qualities play a major role in structuring sheep/human relationships, yet they have shown a remarkable degree of genetic flexibility in response to domestication and selective breeding, as well as to importation into isolated environments like islands. These factors manifest in the qualities of the wool, as do their more immediate conditions, like temporary stress or access to resources at a given time. A fleece of any quality is also affected by the way in which the sheep is shorn. Wool, then, is an emergent archive that indexes millennia of breeding, adaptation to environmental conditions, and 
responses to current conditions, husbandry, and shearing practices. The process of making with wool, if the maker is said to be the one who follows the material, properly starts with sheep husbandry, for the decisions made by sheep growers reflect the kind of workmanship outlined by Pye, the ability to recognize the qualities of raw material and develop them until they can be said to be "good material". In this case, it means selective breeding for wool qualities and husbandry and shearing practices to ensure the health of the sheep and intact, clean fibers.

The Estonian native sheep is not a formally recognized breed (although there are efforts to change this). They have qualities that can be described as archaic - long, double-coated fleeces, small bodies, hardy constitutions, many colors of wool - but they are also variable, with inconsistent wool qualities from individual to individual (Kabun \& Michelson, n.d.). Some stock came from the mainland, but many of these sheep have lived on the island for generations upon generations. In contrast, the Kihnu native sheep is a recognized and protected breed established through widespread genetic testing of Estonian native sheep (Rannamäe et al., 2016, 2020). Intense efforts from the Kihnu Sheep Growers' Association (www.kihnumaalammas.eu) and its leader, Anneli Ärmpalu-Idvand of Manija Island, have resulted in strict standards for Kihnu native sheep. Sheep on Kihnu generally are not part of the recognized breed, leading to a divide between traditional sheep husbandry and wool crafts on the island on one hand and sheep that bear the island's name and sense of antiquity on the other.

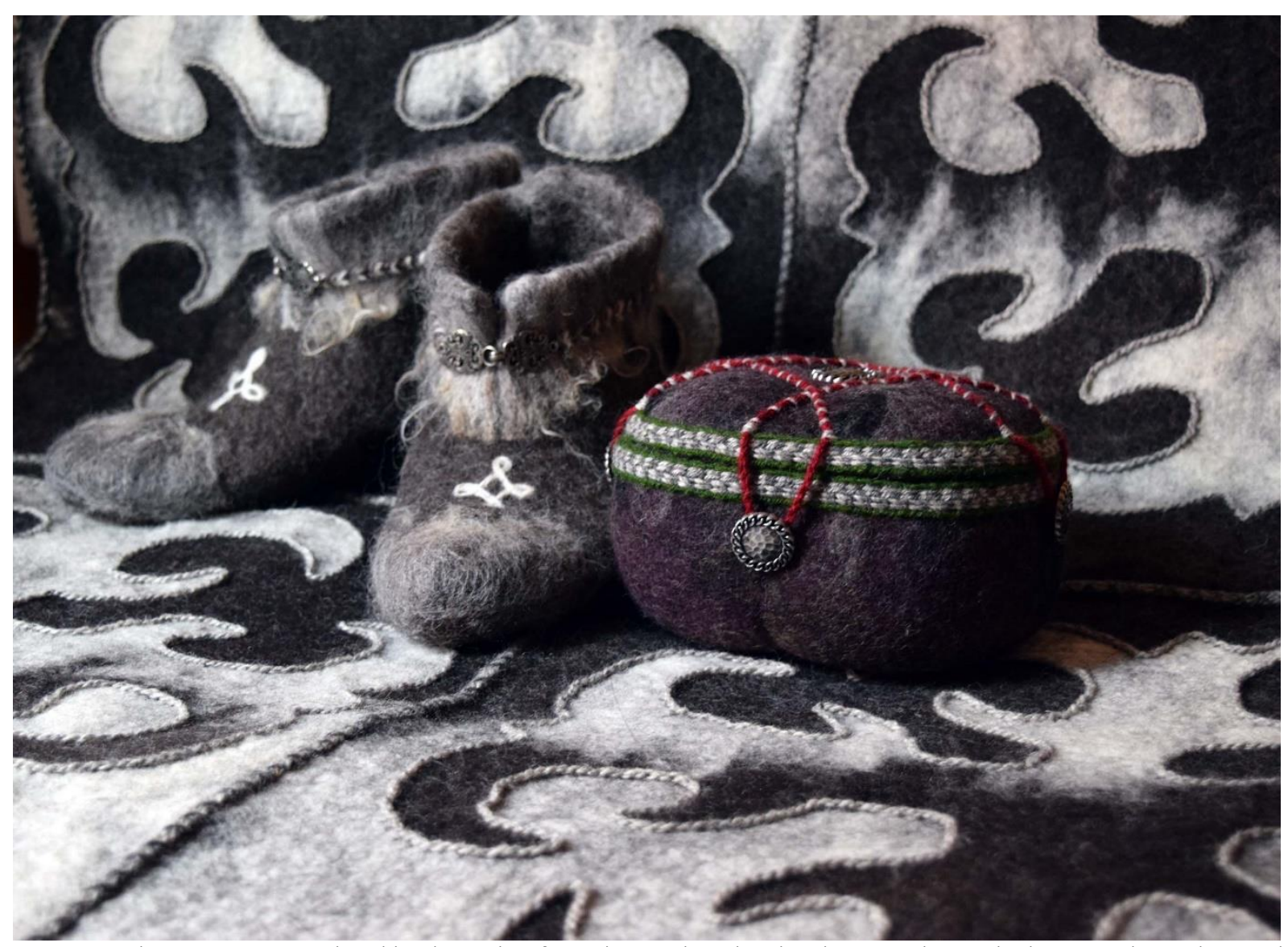

FIGURE 4 Felting projects completed by the author for a class at the Viljandi Culture Academy. The large textile used Central Asian techniques (shyrdak) and both Kihnu native sheep wool (black and grey) and Merino wool (white). The juxtaposition of the two fibers allowed close comparison of their qualities during and after the felting process.

While wool crafts on Kihnu most often follow traditional structures, techniques, and design principles, crafts involving the wool of Kihnu native sheep have a much broader range. One highly visible use is in wet felting, in which wool is used to create dense, often sculptural forms using water and agitation. Through my own practice, I have seen that Kihnu native sheep wool readily condenses into a dense, 
uniform felt with a soft surface that maintains hints of its double-coated texture. However, Estonia does not have an ancient tradition of wet felting, so felted objects may draw from other traditions, including those from the Middle East and Central Asia, that give a general impression of traditional craft bolstered by the scientifically established antiquity of the Kihnu native sheep. One notable Estonian artist, Erika Pedak (villavolli.ee), uses Kihnu wool in felted items that often are experimental and sculptural, including large, artistic wall hangings with wild tentacles and a profusion of pockets - in these works, archaic native wool takes on forms that have no visible connection with traditional crafts. However, they play a vital role in promoting conservation of these ancient sheep as part of Estonia's agrobiodiversity. Pedak does not raise the sheep herself but obtains the wool through a direct family connection on Saaremaa island, where her studio is also located, and so the collaboration between artist, materials, shepherd, and sheep is intimate, allowing them to make-with in a sympoeitic entanglement, and yet they all are comparatively distant from the physical and cultural environment of Kihnu.

\section{CONCLUSION}

Although making things with wool is an emergent process that weaves together many different strands of meaning, materials, environments, histories, animals, and individuals, the degree of entanglement varies. Dropped or broken threads can bring a sense of freedom or one of loss or estrangement, depending on one's perspective.

For Kihnu islanders, wool crafts intertwine with traditional husbandry practices, the cultural landscape, community sociability, traditional dress, music and dance, and a shared set of aesthetics and values around making. They also manifest changing patterns of life and economy: sold to visitors and worn out of context, handmade woolen items represent an investment of time and skill that leaves the island, likely never to return. Like the Kihnu native sheep, once their value was more widely perceived, many were taken far from their native environment. At the same time, the vitality of native sheep and wool on Kihnu is clear, as both enjoy deep, multifarious relationships with the island's most valued cultural practices and everyday life.

As a researcher, spinning with Kalju Elvi, knitting at Metsamaa, and practicing wool crafts on my own are all valid methods to gain a better understanding of life and making on Kihnu, but they are also methods for making-with, developing a sense of connection not only with the island's living inhabitants, but also with those who created the many intricate items in Estonian museums. Using the wool of Kinnu native sheep, I experience qualities and limitations of the material that teach me how to enter its flow. With my spinning wheel, so similar to Kalju Elvi's wheel, and Kihnu wool carded on hand cards like hers, I find that the material, technique, and tools work together to easily, almost naturally, spin a yarn that is a standard diameter for Kihnu handicrafts - use a single strand for weaving skirts, ply two together for stockings and mittens, and three for heavy work socks. Does the wheel determine the type of yarn, or did the type of yarn determine the design of the wheel? An interesting question, but it makes little difference in the actual process of making: a collaboration of materials, tools, animals, landscapes, hands and minds, both of the present and the past, that unfolds in the moment as twist entering fiber and fiber flowing through the hands, a wheel spinning and a promise of warmth from a sheep's gift.

\section{ACKNOWLEDGEMENTS}

Thank you to the great craftswomen of Kihnu, and particularly to Kolde Külli, Kalju Elvi, Miku Vivika, and Maie Aav. Many thanks are also due to the Viljandi Culture Academy for facilitating my work in Estonia, and particularly to Ave Matsin and Elo-Hanna Seljamaa. 


\section{REFERENCES}

Bennett, J. (2010). Vibrant matter : a political ecology of things. Duke University Press.

Bird-David, N. (1999). “Animism” Revisited. Current Anthropology, 40(S1), S67-S91. https://doi.org/10.1086/200061

Candy, L., \& Edmonds, E. (2018). Practice-Based Research in the Creative Arts: Foundations and Futures from the Front Line. Leonardo, 51(1), 63-69. https://doi.org/10.1162/LEON_a_01471

Coole, D., \& Frost, S. (2010). Introducing the New Materialisms. In D. Coole \& S. Frost (Eds.), New Materialisms (pp. 1-44). Duke University Press. https://doi.org/10.1515/9780822392996-002

Glassie, H. (2007). Passing the time in Ballymenone : culture and history of an Ulster community. Indiana University Press.

Haraway, D. (2016). Staying with the trouble: making kin in the Chthulucene. Duke University Press.

Ingold, T. (2015). An Ecology of Materials. In S. Witzgall \& K. Stakemeier (Eds.), Power of Material/ Politics of Materiality (1. edition, pp. 59-66). Diaphanes.

Kabun, K., \& Michelson, A. (n.d.). Villa tüübid. Maalammas. https://sites.google.com/site/eestimaalammas/villatueuebid?authuser $=0$

Kuutma, K. (2002). National Candidature File for Estonia: The Kihnu Cultural Space. UNESCO.

Pukk, M. (2019). Printed-pattern headscarves in Kihnu cultural space. Studia Vernacula, 11, 78-101.

Pye, D. (2015). The nature and art of workmanship (Reprint). Bloomsbury Academic.

Rannamäe, E., Lõugas, L., Speller, C. F., Valk, H., Maldre, L., Wilczyński, J., Mikhailov, A., \& Saarma, U. (2016). Three Thousand Years of Continuity in the Maternal Lineages of Ancient Sheep (Ovis aries) in Estonia. PLOS ONE, 11(10).

Rannamäe, E., Saarma, U., Ärmpalu-Idvand, A., Teasdale, M. D., \& Speller, C. (2020). Retroviral analysis reveals the ancient origin of Kihnu native sheep in Estonia: implications for breed conservation. Scientific Reports, 10(1), 1-8. https://doi.org/10.1038/s41598-020-74415-z

Reinholm, V. (2013). Anu Raud : Eesti tekstiilikunstnik = Anu Raud Estonian textile artist. Valgus.

Ryder, M. L. (2007). Sheep and man (2. impr.). Duckworth.

Statistikaamet. (2020). Kihnu rural municipality. https://www.stat.ee/index.php/en/find-statistics/statisticsregion/parnu-county/kihnu-rural-municipality

Summatavet, K. (2005). Folk tradition and artistic inspiration: a woman's life in traditional Estonian jewelry and crafts as told by Anne and Roosi. University of Art and Design Helsinki.

UNESCO. (n.d.). Kihnu cultural space. Intangible Cultural Heritage. https://ich.unesco.org/en/RL/kihnu-culturalspace-00042

Vill. KL 31. (1941). Korrespondentide Vastused, ERM KV 61, Eesti Rahva Muuseum, Tartu, Estonia.

Vosters, H. (2014). Military Memorialization and its Object(s) of Period Purification. In M. Schweitzer \& J. Zerdy (Eds.), Performing Objects and Theatrical Things (pp. 104-117). Palgrave Macmillan. https://doi.org/10.1057/9781137402455

Wisnoski, B. (2019). An Aesthetics of Everything Else: Craft and Flat Ontologies. Journal of Modern Craft, 12(3), 205-217. https://doi.org/10.1080/17496772.2019.1678867 